\title{
Cellulose Acetate and Electroendosmosis-Low Agarose Electrophoresis: \\ Advanced Methods for the Separation and Quantitative Determination of Serum Creatine Kinase Isoenzyme Levels
}

\author{
By E. SiragEldin \\ Abteilung für Klinische Chemie der Medizinischen Universitätsklinik Hamburg \\ G. Gercken
}

Institut für Biochemie und Lebensmittelchemie der Universität Hamburg

K. Harm

Zentrallabor des Allgemeinen Krankenhauses Heidberg, Hamburg and

K. D. Voigt

Abteilung für Klinische Chemie der Medizinischen Universitätsklinik Hamburg

(Received August 7/December 6, 1984)

\section{Summary:}

1. Two methods for the separation and demonstration of creatine kinase isoenzymes are described i.e. electrophoresis on cellulose acetate and on electroendosmosis-low agarose.

2. The fluorescence of NADPH as an indicator for the creatine kinase bands was used in both methods.

3. The methods proved to be specific, reliable and highly reproducible, and allow a rather large number of samples $(12-18)$ to be analysed in one run within a relatively short time.

4. The prominent advantage of the proposed methods over others is their extreme sensitivity. Both methods allow linear quantification of creatine kinase isoenzymes up to $700 \mathrm{U} / 1$ at $25^{\circ} \mathrm{C}$ with a lower detection limit of $3 \mathrm{U} / \mathrm{l}$, using a minute amount of sample $(2 \mu \mathrm{l})$.

5. The diagnostic value of the methods was shown by their application to sera of patients with myocardial infarction or other diseases.

Cellulose-Acetat-Folien- und Elektroendosmose-low-Agarose-Gel-Elektrophorese:

Weiterëntwickelte Methoden für die Trennnung und quantitative Bestimmung von Kreatinkinase-Isoenzymen im Serum

\section{Zusammenfassung:}

1. Die Elektrophorese auf Cellulose-Acetat-Folie und Elektroendosmose-low-Agarose-Gel werden als Methoden für Trennung und Nachweis von Kreatinkinase-Isoenzymen beschrieben.

2. Indikator der Kreatinkinase-Isoenzym-Banden ist in beiden Verfahren die NADPH-Fluoreszenz. 
3. Die Methoden erweisen sich als spezifisch, zuverlässig und gut reproduzierbar. Sie ermöglichen die Analyse von 12-18 Proben in einem Lauf in etwa 30 Minuten.

4. Ihr wesentlicher Vorteil ist ihre bemerkenswerte Empfindlichkeit: Beide Methoden erlauben eine Quantifizierung von Kreatinkinase-Isoenzymen in einem linearen Bereich bis zu $700 \mathrm{U} / \mathrm{l}$ bei $25^{\circ} \mathrm{C}$ bei einer unteren Nachweisgrenze von $3 \mathrm{U} / \mathrm{l}$, wobei das benötigte Probenvolumen $2 \mu \mathrm{l}$ beträgt.

5. Der diagnostische Wert wird an Seren von Patienten mit und ohne Myocardinfarkt únd von ausgesuchten Tumorkranken belegt.

\section{Introduction}

The enzyme creatine kinase (ATP: creatine phosphotransferase, EC 2.7.3.2.) catalyses the reaction:

$$
\begin{aligned}
\operatorname{MgATP}^{2(-)} & + \text { Creatine } \rightleftharpoons \mathrm{MgADP}^{(-)} \\
& + \text {Phosphocreatine } \\
& (-)+\mathrm{H}^{(+)}
\end{aligned}
$$

The enzyme is a dimeric molecule being widely distributed among muscular tissues $(1-3)$. At least three creatine kinase dimers exist in the cytoplasm (4), namely muscular type (MM), brain type (BB), and cardiac type (MB). Further variants designated as macro creatine kinase were described as IgG-linked creatine kinase (type 1) and oligmeric forms of mitochondrial creatine kinase (type 2) $(5-8)$. However, as the isoenzymes are relatively tissue specific, their measurement in serum has become clinically a valuable procedure for the diagnosis of muscular disorders $(9-11)$. Widely divergent results have been obtained for the quantitative distribution of the creatine kinase variants in sera (7); this is explained, at least partly, by the limitations of the electrophoretic method used:

1. The nonspecific staining with tetrazolium salt is relatively unreliable for demonstration of the respective isoenzyme in the low activity range.

2. The inactivation of the isoenzyme may occur, owing to the lack of or to limited amounts of thiol compounds in the electrophoretic medium.

3. In a coupled enzyme assay, the introduction of coupling enzymes into the gel in the staining solution leads to a substantial diminution in the sensitivity of the method.

In this paper techniques for electrophoresis on cellulose acetate and electroendosmosis-low agarose are described which render them adaptable to both routine and research purposes for separation and quantitative determination of creatine kinase isoenzymes.

\section{Materials and Methods}

Dithiothreitol and CPK-ISOTROL were obtained from Sigma Chemie, München, CK ISOENZYME CONTROL SERUM Lot No. 071Y02 from Ortho. CK-NAC activated and CKMB NAC activated test kits from Boehringer Mannheim. 5.5Diethylbarbituric acid and magnesium acetate were purchased from Merck, Darmstadt, Agarose EEO high from Serva Feinbiochemica, Heidelberg. Isogelagarose-EF and agarose-M were obtained from LKB, Bromma. Agarose-IEF was obtained from Pharmacia Fine Chemicals, Uppsala. Cellulose acetate strips (Sartorius membrane filter type SMN 11200 BD $5.7 \times 4.5 \mathrm{~cm}$ ) were obtained from Beckman, München, Sartorius membrane filter type SM 11300 from Sartorius, Göttingen.

Quantitative determination of creatine kinase catalytic activities

The optimized spectrophotometric method on the recommendations of the German Society for Clinical Chemistry (12) was used to measure total creatine kinase with a Hitachi Rate Analyzer at $25^{\circ} \mathrm{C}$, creatine kinase-MB was determined at $25^{\circ} \mathrm{C}$ after immunoinhibition of creatine kinase- $M$ subunits by specific antibodies.

\section{Electrophoresis}

\section{Cellulose acetate}

Electrophoresis was carried out on cellulose acetate strips in $73 \mathrm{mmol} / \mathrm{l}$ tris-base, $24 \mathrm{mmol} / \mathrm{l}$ barbituric acid and $1 \mathrm{mmol} / \mathrm{l}$ dithiothreitol at $\mathrm{pH}$ 8.6. The cellulose acetate strips (equilibrated in the buffer described above) were blotted between filter papers and mounted on a Boskamp microphor chamber. Samples of 1 to $2 \mu \mathrm{l}$ tissue extract or serum were applied using a disposable nonheparinized $5 \mu \mathrm{l}$ capillary tube. Electrophoresis was performed in a cold room $\left(6-8^{\circ} \mathrm{C}\right)$ at 300 volts for $35 \mathrm{~min}$.

\section{Electroendosmosis-low agarose}

The procedure for the preparation of thin layer gel $(0.5 \mathrm{~mm})$ as described elsewhere (13) was used here with the following modifications:

a) The glass plates were washed with detergent and methanol.

b) To obtain small wells for the application of samples, small pieces of $2 \times 4 \mathrm{~mm}$ Rotex label tape were cut and mounted on glass plates $(125 \times 240 \times 3 \mathrm{~mm})$ with a spacer at a distance of $4 \mathrm{~cm}$ from the cathodic side. The glass was then left overnight to dry.

c) The electrophoretic gels were composed of $10 \mathrm{~g} / 1$ agarose in $73 \mathrm{mmol} / \mathrm{l}$ tris-base and $24 \mathrm{mmol} / \mathrm{l}$ barbituric acid at a $\mathrm{pH}$ 8.6. The agarose suspension was boiled in a water bath for $10 \mathrm{~min}$ and cooled to $70^{\circ} \mathrm{C}$. . : 
d) 2-Mcrcaptocthanol with a final concentration of $2.6 \mathrm{mmol} / \mathrm{1}$ was added to $20 \mathrm{ml}$ agarose solution at $65^{\circ} \mathrm{C}$, mixed and injected between the glass plates. The sample application was performed as described for the cellulose acetate procedure. The tissue extracts and serum samples were subjected to electrophoresis at $6-8^{\circ} \mathrm{C}$ in a LKB-2117 Multiphor chamber for $35 \mathrm{~min}$ at 300 volts using tris barbituric acid buffer supplemented with $1 \mathrm{mmol} / \mathrm{l}$ dithiothreitol.

Visualisation of creatine kinase isoenzymes, using fluorescence staining technique

\section{Cellulose acetate}

For the staining of cellulose acetate strips the following solutions were prepared:

1. One volume of $20 \mathrm{~g} / \mathrm{l}$ agar purum in distilled water was heated to boiling and transferred to a water bath a $43^{\circ} \mathrm{C}$.

2. One volume of the reaction medium for the quantitative determination of creatine kinase was concentrated three fold in $0.1 \mathrm{mmol} / 1$ imidazole buffer at a $\mathrm{pH} 6.7$ and kept at $37^{\circ} \mathrm{C}$. The two solutions 1 and 2 were mixed together and poured onto $94 \times 84 \mathrm{~mm}$ glass plates. After electrophoresis the cellulose acetate strips were placed inverted onto the gel and incubated at $37^{\circ} \mathrm{C}$ for $35 \mathrm{~min}$. The strips were then dried by a stream of cold air and inspected under a fluorescent lamp at $360 \mathrm{~nm}$ to locate the enzyme bands. The fluorescent bands at the site of creatine kinase activity were scanned within an hour with a Beckman model CDS-200 densitometer.

\section{Agarose films}

After electrophoresis the agarose film was removed and placed on a glass plate as carrier. A piece of Sartorius membrane filter type SM 11200 was cut and placed in a staining dish containing solution 2 concentrated 1.5 fold. After soaking, excess reagent was removed and the membrane was fixed on the agarose film by means of a clean squeegee avoiding entrapment of air, placed in a humidity chamber and incubated for $35 \mathrm{~min}$ at $37^{\circ} \mathrm{C}$. Both agarose film and membrane sheet were then dried separately with a stream of cold air and inspected under UV illumination to locate the bands.

\section{Blood samples}

The samples were obtained from patients attending the intensive care unit and from out-patients. Included were specimens from patients suffering from myocardial infarction as well as patients having no myocardial affection. Blood was centrifuged immediately and the serum obtained stored at $4^{\circ} \mathrm{C}$ before electrophoretic separation and quantification of isoenzymes. Specimens not analysed on the same day were stored at $-20^{\circ} \mathrm{C}$, analysed within one hour after thawing.

\section{Evaluation of electrophoretic methods}

In order to establish the detection limit and to examine the linearity of both methods, dilution series were prepared from specimens containing creatine kinase-MM and creatine kinaseMB isoenzymes, using electrophoretic buffer containing $1 \mathrm{~g} / \mathrm{l}$ bovine serum albumin as diluent. Each dilution was assayed for total creatine kinase and creatine kinase-MB by the immunoinhibition test. Two microliters were applied for each dilution to both cellulose acetate and agarose film for electrophoresis (each dilution series was analysed ten times for statistical purposes). The peaks obtained for each dilution were then scanned under automatic zero and automatic peak delimiting settings. Two microliters of creatine kinase-inactivated serum (heated at $56^{\circ} \mathrm{C}$ for three hours) were also analyed as above. To evaluate the within-run precision, a commercial control material was analysed as described above. To assess the variation contributed by the densitometer, a single pattern of the commercial control material (Sigma) was scanned ten times with manual, with automatic zero and automatic peak delimiting settings.

\section{Results}

\section{Detection limit and linearity}

The sensitivity of both methods was estimated as described above by preparing dilution series from samples obtained from patients with proven myocardial infarction (tab. 1 and fig. 1). With two microliter samples, the densitometer response was linear with total catalytic activity concentration up to $700 \mathrm{U} / 1$ at $25^{\circ} \mathrm{C}$. This designated the upper limit of both cellulose acetate and agarose electrophoresis. The measured creatine kinase-MB levels in both methods correlate well with total creatine kinase catalytic activity (tab. $1, r=0.995$ for cellulose acetate and $r=0.997$ for agarose). Furthermore the CV tends to increase with decreasing activity of creatine kinase-MB. However, even at a level of $3 U / 1$ it is still acceptably low in both methods. Below $3 \dot{U} / 1$ both methods were relatively insensitive when 2 microliter samples were applied. The smallest value

Tab.1. Comparison of the within-run variation of creatine kinase-MB measured by cellulose acetate and agarose electrophoresis.

\begin{tabular}{lllll}
\hline $\begin{array}{l}\text { Total creatine kinase } \\
(\mathrm{U} / \mathrm{l})\end{array}$ & \multicolumn{4}{l}{ Creatine kinase-MB } \\
\cline { 2 - 5 } & $\mathrm{n}$ & $\overline{\mathrm{x}}$ & $\mathrm{SD}$ & $\mathrm{CV}$ \\
& & $(\mathrm{U} / \mathrm{l})$ & $(\mathrm{U} / \mathrm{l})$ & $(\%)$ \\
\hline
\end{tabular}

\section{Cellulose acetate}

$\begin{array}{lrrlr}485 & 10 & 59 & 3.8 & 6.6 \\ 243 & 10 & 29 & 1.7 & 6.0 \\ 118 & 3 & 13 & 0.37 & - \\ 60 & 10 & 6.0 & 0.4 & 6.5 \\ 29 & 10 & 3.0 & 0.35 & 10.7\end{array}$

\section{Agarose}

\begin{tabular}{lrrrr}
471 & 3 & $53(52)$ & 0.97 & 1.8 \\
236 & 10 & $26(27)$ & 1.56 & 6 \\
116 & 10 & $13(12)$ & 0.59 & 4.6 \\
61 & 10 & $6(6.9)$ & 0.48 & 7.7 \\
28 & 8 & $3(3.2)$ & 0.46 & 14.6 \\
\hline
\end{tabular}

Abbreviations: $\mathrm{SD}=$ standard deviation

$\mathrm{CV}=$ coefficient of variation

$\overline{\mathrm{x}}=$ mean

$(\bar{X}=$ results obtained by overlay cellulose acetate membrane on agarose gel. 


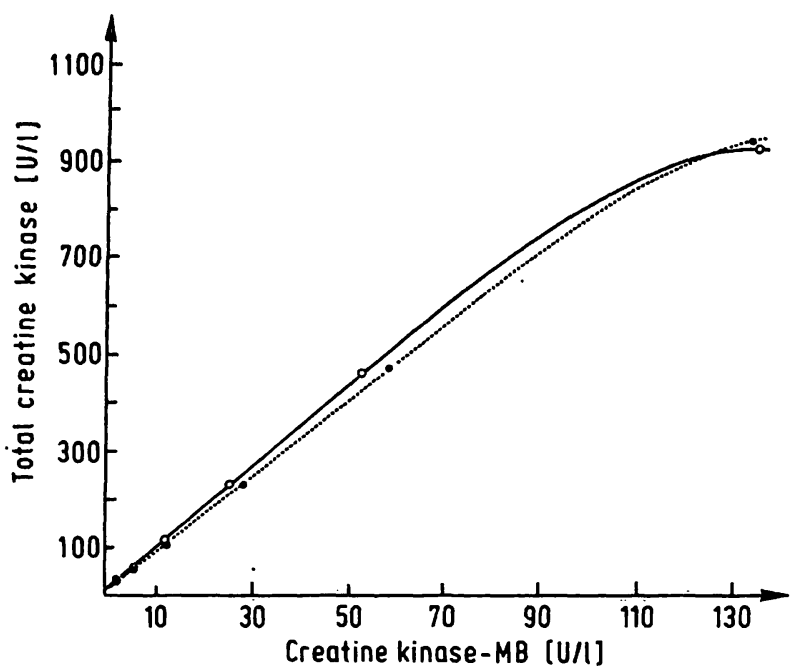

Fig. 1. Measured total creatine kinase and creatine kinase-MB catalytic activity concentration in the recovery-sensitivity and linearity of both cellulose acetate $(\boldsymbol{O}-\mathbf{O})$ and agarose $(\mathrm{O}-\mathrm{O})$ methods.

for creatine kinase that could be distinguished from zero (when two microliter samples were used) at a $95 \%$ confidence level is $3.0 \pm 0.9 \mathrm{U} / 1$ for the agarose and $3.0 \pm 0.7 \mathrm{U} / 1$ for the cellulose acetate method (tab. 1). The results obtained by overlaying cellulose acetate membrane on agarose gel (in brackets) were similar to those found on agarose film.

No variation from zero was observed, when a heattreated creatine kinase-inactivated serum was electrophoresed and scanned as described above.

\section{Within-run precision}

We evaluated within-run precision of both methods by making multiple applications of Ortho Control to both cellulose acetate and agarose gel which were electrophoresed simultaneously. All patterns were scanned using automatic delimiting of peaks and automatic zero settings. The following results were obtained (mean +3 S. D.): creatine kinase-BB $18 \pm 4 \%$, creatine kinase-MB $24 \pm 5 \%$, creatine kinase-MM $58 \pm 6 \%$ using agarose gel and creatine kinase-BB $18 \pm 4 \%$, creatine kinase-MB $25 \pm 3 \%$ and creatine kinase-MM $57 \pm 4 \%$ using cellulose acetate electrophoresis respectively. These results were similar to those obtained by various methods as stated in the assay data of the Ortho Creatine Kinase-Isoenzyme Control Serum Lot No. 071Y02.
To assess the contribution of the densitometer imprecision to within-run uncertainty, we performed repeated scans of single patterns of CPK ISOTROL (Sigma) using automatic delimiting of peaks and zero automatic, as well as manual, to study the contribution of the mode of delimiting to total scanning imprecision. No significant differences were noticed. The CVs $0.56 \%, 0.2 \%, 0.34 \%$ and the means 116 $\mathrm{U} / 1,185 \mathrm{U} / 1,129 \mathrm{U} / \mathrm{l}$ were found for creatine kinase$\mathrm{BB}$, creatine kinase-MB and creatine kinase-MM respectively when the control serum was diluted 4 times.

\section{Between-run precision}

Aliquots of frozen $\left(-20^{\circ} \mathrm{C}\right)$ Sigma control were analysed by both methods over a period of two months to evaluate between-run precision. The results obtained showed no significant differences. The CVs obtained for creatine kinase-MM were $6.1 \%$ and $4.9 \%$ for creatine kinase-MB $4.7 \%$ and $4.2 \%$ for creatine kinase- $\mathrm{BB} 4.7 \%$ and $5.6 \%$ for the agarose and cellulose acetate methods respectively. The means were $129 \mathrm{U} / 1$ and $133 \mathrm{U} / 1$ for creatine kinase-MM, $189 \mathrm{U} / 1$ and $189 \mathrm{U} / 1$ for creatine kinase-MB, 111 $\mathrm{U} / \mathrm{l}$ and $108 \mathrm{U} / \mathrm{l}$ for creatine kinase-BB for agarose and cellulose acetate respectively.

The effect of electroendosmosis on the separation of creatine kinase isoenzymes

The effect of electroendosmosis on the separation of creatine kinase isoenzymes of a patient bearing a bronchial carcinoma is illustrated in figure 2 . The migration distances (from the start to the middle of the band) in $\mathrm{cm}$ obtained for creatine kinase isoenzyme bands, using agarose types with different electroendosmosis, were:

3.8, 4.2 and 5.1 for creatine kinase-BB, $0.0,0.7$ and 1.2 for creatine kinase-MM and $0.0,0.1$ and 0.2 for creatine kinase-MiMi, for high, medium and low electroendosmosis agarose types respectively. The resolution of creatine kinase bands on electroendosmosis-low agarose (agarose IF) is better than on medium and high electroendosmosis agarose types (fig. 2). The electropherograms were traced with a densitometer úsing automatic zero and automatic delimiting of peak settings. The cathodic (mitochondrial?) band observed by electroendosmosis-low agarose (fig. 2a) migrates with creatine kinase-MM in high electroendosmosis agarose (fig. $2 b$ ) and is hardly distinguished from creatine kinase-MM in medium electroendosmosis agarosse (fig. 2c). 

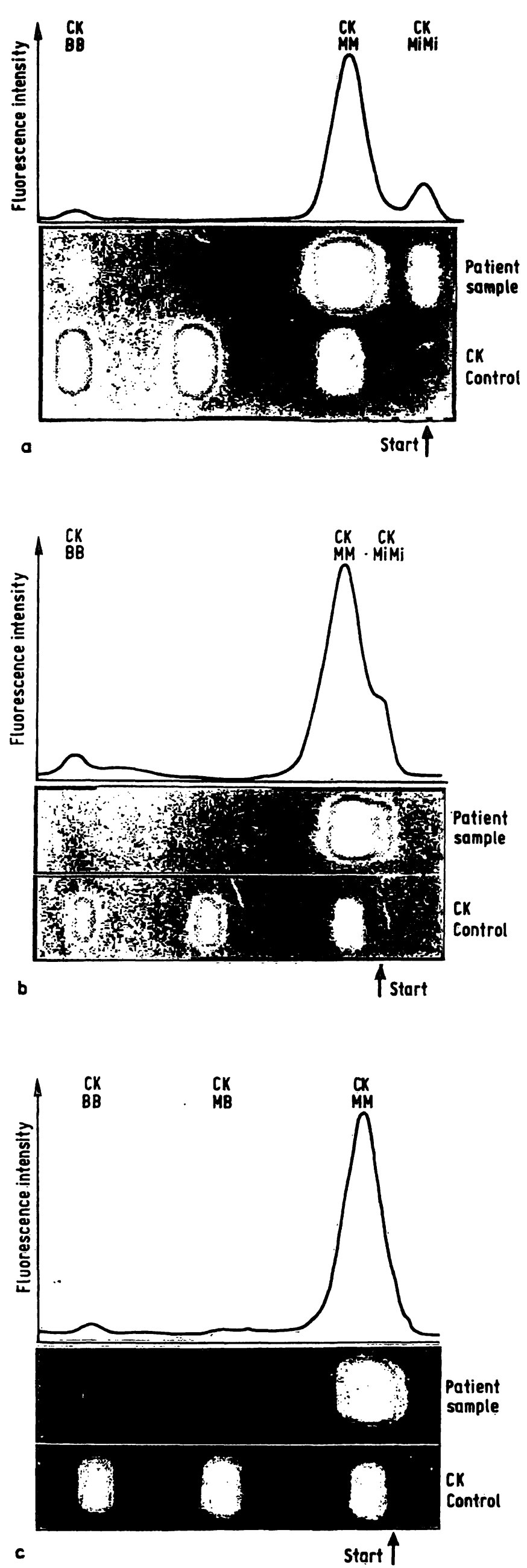

\section{Patients' specimens}

Representative patients' blood samples submitted for creatine kinase to the clinical chemistry laboratory were used to compare the different methods. Patients with proven myocardial infarction as well as no myocardial affection were selected for these studies. All specimens with total creatine kinase catalytic activity concentration greater than $700 \mathrm{U} / 1$ were diluted with electrophoresis buffer or normal saline before electrophoresis was performed. The results obtained are summarized in table 2 and table 3 . In patients with myocardial infarction (tab. 2), values of 7 to $153 \mathrm{U} / 1$ were found for creatine kinase-MB when cellulose acetate and agarose electrophoresis were used. A good correlation ( $r=0.991)$ was found between both methods. This holds true also for the immunoinhibition test for creatine kinase- $M B$ values above $10 \mathrm{U} / \mathrm{l}$. In specimens from 21 patients (tab. 3) with no myocardial affection, having normal and elevated total creatine kinase activities, creatine kinase-MB was determined by the immunoinhibition test, cellulose acetate and agarose electrophoresis. The creatine kinase-MB percentage obtained in this group does not exceed $4 \%$ of the total creatine kinase catalytic activity. Furthermore, the cellulose acetate and agarose methods correlate well with each other $(r=0.997)$. In some patients, however, a good correlation between both electrophoresis methods and the immunoinhibition test was not obtained.

Data from several patients suffering from malignancies is summarized in table 4 . The creatine kinase isoenzyme patterns obtained by cellulose acetate and agarose electrophoresis from patients bearing

a) bronchial carcinoma with massive dissemination in bone and liver,

b) metastatic endometrium carcinoma and

c) metastatic carcinoma of the rectum, respectively, are shown.

Fig. 2. Separation of creatine kinase isoenzymes by electrophoresis on agarose gels with different levels of electroendosmosis. Enzyme activity bands (with a total catalytic activity concentration of $483 \mathrm{U} / \mathrm{l}$ and $129 \mathrm{U} / \mathrm{l}$ of creatine kinase measured with the immunoinhibition test by photometry) were made visible by fluorescence technique and traced with a Beckman model CDS-200 densitometer using automatic delimiting of peaks and automatic zero settings.

a) Electroendosmosis-low agarose (agarose IF)

b) Electroendosmosis-medium agarose (agarose-M)

c) Electroendosmosis-high agarose (agarose EEO high) 
Tab. 2. Creatine kinase isoenzymes in patients with myocardial infarction determined with different methods.

\begin{tabular}{|c|c|c|c|c|c|}
\hline \multirow{3}{*}{$\begin{array}{l}\text { Patient } \\
\text { No. }\end{array}$} & \multicolumn{2}{|l|}{ Continuous methods } & \multicolumn{3}{|l|}{ Electrophoresis } \\
\hline & \multirow[t]{2}{*}{$\begin{array}{l}\text { Total creatine kinase } \\
(\mathrm{U} / \mathrm{l})\end{array}$} & \multirow[t]{2}{*}{$\begin{array}{l}\text { Creatine kinase-MB*) } \\
(\mathrm{U} / \mathrm{l})\end{array}$} & \multicolumn{3}{|c|}{$\begin{array}{l}\text { Creatine kinase-MB } \\
(\mathrm{U} / \mathrm{l})\end{array}$} \\
\hline & & & Cellulose acetate & $\cdot 1$ & Agärose \\
\hline 1 & 1347 & 139 & 137 & & 140 \\
\hline 2 & 1462 & 125 & 163 & & 153 \\
\hline 3 & 1671 & 117 & 142 & & 138 \\
\hline 4 & 427 & 46 & 47 & & 49 \\
\hline 5 & 912 & 85 & 94 & & 105 \\
\hline 6 & 275 & 17 & 18 & $\cdot$ & 21 \\
\hline 7 & 124 & - & 7 & & 10 \\
\hline 8 & 578 & 58 & 46 & & 63 \\
\hline 9 & 440 & 29 & 24 & & 26 \\
\hline 10 & 300 & 20 & 21 & & 20 \\
\hline 11 & 336 & 44 & 50 & & 47 \\
\hline 12 & 671 & 49 & 60 & & 68 \\
\hline 13 & 487 & 29 & 37 & & 38 \\
\hline
\end{tabular}

*) Immunoinhibition test

Tab. 3. Total creatine kinase and creatine kinase-MB percentage in serum of patients without myocardial affection determinèd by different methods.

\begin{tabular}{|c|c|c|c|c|}
\hline \multirow{3}{*}{$\begin{array}{l}\text { Patient } \\
\text { No. }\end{array}$} & \multicolumn{2}{|l|}{ Continuous methods } & \multicolumn{2}{|l|}{ Electrophorèsis } \\
\hline & \multirow[t]{2}{*}{$\begin{array}{l}\text { Total creatine kinase } \\
(\mathrm{U} / \mathrm{l})\end{array}$} & \multirow[t]{2}{*}{$\begin{array}{l}\text { Creatine kinase-MB*) } \\
(\%)\end{array}$} & \multicolumn{2}{|l|}{$\begin{array}{l}\text { Creatine kinase-MB } \\
(\%)\end{array}$} \\
\hline & & & Cellulose acetate & Agarose \\
\hline 1 & 80 & - & - & $=$ \\
\hline 2 & 75 & - & - & - \\
\hline 3 & 78 & - & - & $\div$ \\
\hline 4 & 84 & - & - & - \\
\hline 5 & 93 & - & - & $=$ \\
\hline 6 & 126 & - & - & - \\
\hline 7 & 132 & - & $\ldots$. & - \\
\hline 8 & 191 & - & 2.7 & 2.7 \\
\hline 9 & 212 & - & 2.0 & 2.0 \\
\hline 10 & 209 & - & 0.0 & 0.1 \\
\hline 11 & 229 & - & 1.0 & 0.4 \\
\hline 12 & 301 & 4.6 & 3.0 & 3.2 \\
\hline 13 & 309 & 3.8 & 3.2 & 3.7 \\
\hline 14 & 230 & - & - & - \\
\hline 15 & 457 & 2.6 & 2.9 & 2.4 \\
\hline 16 & 435 & - & - & - \\
\hline 17 & 586 & 2.7 & 3.6 & 3.2 \\
\hline 18 & 592 & 4.0 & 3.4 & \\
\hline 19 & 875 & 4.2 & 4.3 & 4.2 \\
\hline 20 & 1316 & 1.6 & 1.6 & 1.5 \\
\hline 21 & 2832 & 0.8 & 1.0 & 1.4 \\
\hline
\end{tabular}

*) Immunoinhibition test

In all three patients, an electrophoretically abnormal (cathodic) creatine kinase band was observed. In addition to the atypical creatine kinase isoenżyme, creatine kinase-MB, creatine kinase- $\mathrm{BB}$, and creatine kinase-MM were observed in the patient with bronchial carcinoma. In case c) the serum creatine kinase-MB activity obtained by the im- munoinhibition test (tab. 4) is almost double that of the total creatine kinase catalytic activity. Further incubations of this sample with anti-M antibodies (obtained from Merck, FRG) before electrophoresis did not inhibit or reduce the intensity of the apparent creatine kinase-MM? and the cathodic band (creatine kinase-MiMi) in the electropherogram. 
Tab. 4. Quantitative analysis of creatine kinase isoenzymes in patients with malignancies.

Continuous methods

\begin{tabular}{|c|c|c|}
\hline & $\begin{array}{l}\text { Total } \\
\text { creatine } \\
\text { kinase } \\
(U / 1)\end{array}$ & $\begin{array}{l}\text { Creatine } \\
\text { kinase-MB*) } \\
(\mathrm{U} / \mathrm{I})\end{array}$ \\
\hline $\begin{array}{l}\text { Bronchial carcinoma } \\
\text { Metastatic endometrium carcinoma } \\
\text { Metastatic rectum carcinoma }\end{array}$ & $\begin{array}{l}651 \\
150 \\
151\end{array}$ & $\begin{array}{l}235 \\
207 \\
294\end{array}$ \\
\hline
\end{tabular}

Electrophoresis

Agarose

\begin{tabular}{|c|c|c|c|c|}
\hline & \multicolumn{4}{|c|}{ Creatine kinase } \\
\hline & $\begin{array}{l}-M M \\
(\%)\end{array}$ & $\begin{array}{l}-\mathrm{MB} \\
(\%)\end{array}$ & $\begin{array}{l}-\mathrm{BB} \\
(\%)\end{array}$ & $\begin{array}{l}\text {-MiMi? } \\
(\%)\end{array}$ \\
\hline \multirow{4}{*}{$\begin{array}{l}\text { Bronchial carcinoma } \\
\text { Metastatic endometrium carcinoma } \\
\text { Metastatic rectum carcinoma } \\
\text { Cellulose acetate }\end{array}$} & $\begin{array}{l}80.3 \\
36 \\
47 ?\end{array}$ & $\begin{array}{l}2.7 \\
- \\
-\end{array}$ & $\begin{array}{l}5.7 \\
- \\
-\end{array}$ & $\begin{array}{l}11.3 \\
64 \\
53\end{array}$ \\
\hline & & & & \\
\hline & \multicolumn{4}{|c|}{ Creatine kinase } \\
\hline & $\begin{array}{l}-M M \\
(\%)\end{array}$ & $\begin{array}{l}-\mathrm{MB} \\
(\%)\end{array}$ & $\begin{array}{l}-B B \\
(\%)\end{array}$ & $\begin{array}{l}\text {-MiMi? } \\
(\%)\end{array}$ \\
\hline $\begin{array}{l}\text { Bronchial carcinoma } \\
\text { Metastatic endometrium carcinoma } \\
\text { Metastatic rectum carcinoma }\end{array}$ & $\begin{array}{l}84 \\
37 \\
51.5 ?\end{array}$ & $\begin{array}{l}3.4 \\
- \\
-\end{array}$ & $\begin{array}{l}5.6 \\
- \\
-\end{array}$ & $\begin{array}{l}6.9 \\
62 \\
48.5\end{array}$ \\
\hline
\end{tabular}

*) Immunoinhibition test

It should be emphasized that in this group, the values obtained for the creatine kinase-BB and mitochondrial bands multiplied by a factor of 2 and added to that of creatine kinase-MB give the same results as obtained by immunoinhibition.

\section{Discussion}

Various studies have been carried out to analyse the multiple forms of creatine kinase found in different animal species $(1,2)$ and human serum $(1,9-11)$. It is well established that the measurement of creatine kinase-MB in serum is an ex excellent test with a high predictive value for the diagnosis of an acute myocardial infarction (10). We describe here methods for electrophoresis on cellulose acetate membranes and electroendosmosis-low agarose gels which are specific, rapid, and gave high resolution of creatine kinase isoenzymes from biological extracts and human sera. To identify the bands obtained, the fluorescence technique was applied. With both methods, the fluorescent bands are clear, specific, intensive and with low interfering background, thus allowing a good qualitative and quantitative estimation of the respective enzyme activities. Furthermore, the background fluorescence in both methods was even and produced a satisfactory base line on the scan tracing. No interference by either albumin or bilirubin was observed in the described methods. A value of $300 \mathrm{mg} / \mathrm{l}$ bilirubin did not alter the base line response of the densitometer (results not shown). The phenomenon of apparently higher creatine kinase-MB catalytic activities than the expected in recovery experiments $(14,15)$, including heat-inactivated sera which contain no creatine kinase-MB catalytic activity, was also observed here. Further experiments dealing with this problem showed that after starting the reaction, at least $5 \mathrm{~min}$ were necessary to estimate a relatively true value for total creatine kinase activity. Using this procedure, both methods gave good results compared with those obtained by using electrophoresis buffer-albumin as diluent.

In terms of technical performance, cellulose acetate, in contrast to agarose electrophoresis, is easy to perform and no further steps are necessary for preparation and staining. Agarose showed a relatively better resolution than cellulose acetate (fig. 2), but it is time-consuming with respect to preparation and drying. Therefore, the application of the overlay cellulose acetate membranes was introduced to

a) overcome the drying problem,

b) allow even distribution of the reaction medium over the whole agarose film,

c) allow a quantitative scanning and

d) allow photographic documentation.

The results obtained correlate well with agarose film $(r=0.995)$ (tab. 1). However, creatine kinase-MB catalytic activity concentrations below $3 \mathrm{U} / 1$ were difficult to assess precisely by both methods, mainly due to the low signal to noise ratio of creatine kinaseMB fluorescence bands compared with the background fluorescence using two microliter samples.

With the reference to the specificity of these two methods, no adenylate kinase catalytic activity was observed in human tissue extracts (muscle and heart) and sera when creatine phosphate was omitted from the reaction medium. The good resolution and the remarkable sensitivity of both methods used may be due to the fact that electroendosmosis-low agarose and cellulose acetate contain very few ionized groups, thus preventing the absorption of biological material to the separation medium (16). 
The advantage of using electroendosmosis-low agarose over other types is obvious from the data in figure 2 which clearly demonstrate the effect of electroendosmosis on the separation of creatine kinase isoenzymes. Cellulose acetate and low electroendosmosis agarose (IF) electrophoresis give better resolution than medium and high electroendosmosis. This may partly explain the divergent results concerning creatine kinase isoenzymes in tissue and sera. The creatine kinase isoenzymes are labile and undergo a rapid, partly oxidative and partly temperature-dependent inactivation $(17,18)$. The oxidative inactivation could be minimized by addition of thiol compounds to the separation medium, to the electrophoresis buffer and the incubation medium. The observation that abnormal migration of fish muscle creatine kinase was completely abolished by addition of dithiothreitol to the electrophoresis medium is in line with our data (19). The second type of inactivation, however, being irreversible, demands careful control of the prevailing temperature. It is known that an electrophoresis at ambient temperature $\left(20-30^{\circ} \mathrm{C}\right)$ causes an inactivation of both creatine kinase-MB $(25-50 \%)$ and creatine kinase-BB $(40-100 \%)$ isoenzyme activities, compared to electrophoresis at $4^{\circ} \mathrm{C}(17,18)$.

\section{References}

1. Lang, H. (1981) Creatine kinase, pathophysiology and clinical application, Springer-Verlag, Berlin, Heidelberg, New York.

2. Keutel, H.J., Okbe, K., Jacobs, H.K., Ziter, F., Maland, L. \& Kuby, S.A. (1972) Arch. Biochem. Biophys. 150, 648-678.

3. Watts, D. C. (1973) In: The enzymes (Boyer, P. D., ed.) 3rd Ed. Vol. 8 , pp. $383-455$.

4. Dawson, D. M., Eppenberg, H. M. \& Kaplan, N. O. (1965) Biochem. Biophys. Res. Commun. 21, 346-353.

5. Report on the workshop of the German Society for Clinical Chemistry. September 19-21, (1983) J. Clin. Chem. Clin. Biochem. 21, 859-876.

6. Lang, H. \& Würzburg, U. (1982) Clin. Chem. 28, $1439-1447$.

7. Kwang, T. C. \& Arvan, D. A. (1981) Clin. Chim. Acta 115 , $3-8$.

8. Jockers-Wretou, E. \& Plessing, E. (1979) J. Clin. Chem. Clin. Biochem. 17, $731-737$.

9. Roberts, R. \& Sobel, B.E. (1973) Ann. Intern Med. 79, $741-742$.

10. Roberts, R. \& Sobel, B.E. (1978) Am. Heart. J. 95, $521-528$.

11. Bendz, R. \& Strom, S. (1981) Scand. J. Thor. Cardiovasc. Surg. 15, 199-204.
In some patients with suspected myocardial infarction, however, the immunoinhibition test (creatine kinase-MB) can be misleading, owing to the presence of creatine kinase variants which are not inhibited by anti-M antibodies (tab. 4). This lack of specificity was also observed in column chromatography $(20,21)$. Additionally, the immunoinhibition test lacks reproducibility at lower creatine kinase-MB levels (below $10 \mathrm{U} / \mathrm{l}$ ). Therefore, the application of sensitive and specific electrophoresis methods (cellulose acetate, agarose) is meaningful in cases where either creatine kinase-BB and or macro creatine kinase prevails or higher sensitivity is required $(22,23)$. The same is true for some patients with various types of carcinoma $(23-25)$.

We conclude that the potential advantages of these two methods employing direct fluorescence scanning, are:

1. reproducibility,

2. reliability,

3. sensitivity, rapidity $(12-18$ samples may be evaluated within 1.5 hours) and

4. specificity.
12. Recommendations of the German Society for Clinical Chemistry (1977) J. Clin: Chem. Clin. Biochem. 15, 255-260.

13. LKB Application Note No. 1818.

14. Hamilton, S. R., Wismatt, T., Torrier, R., \& Rock, R.C. (1979) Clin. Chim. Acta 91, 285-294.

15. Edelman, B., Koch, T. R. \& Raab, C. (1981) Clin. Biochem. $14,39-44$

16. Grubb, A. (1973) Anal. Biochem. 55, 582-592.

17. Morin, L. G. (1977) Clin. Chem. 23, 646-652.

18. Morin, L. G. (1977) Clin. Chem. 23, 205-210.

19. Cann, J.R., Fink, N.H. \& Winzor, D.J. (1983) Arch. Biochem. Biophys. 221, 57-63.

20. Fiolet, J.W.T., Willbrands, A. F., Lie, K. I. \& Terewelle, H. F. (1977) Clin. Chim. Acta 80, 23-35.

21. Lott, J.A. \& Stang, J.M. (1980) Clin. Chem. 26, $1241-1250$.

22. Harm, K., SiragEldin, E. \& Voigt, K. D. The Fourth International Congress on Clinical Enzymology, Arlington 1983.

23. SiragËldin, E., Gercken, G. \& Voigt, K.D. (1982) J. Clin. Chem. Clin. Biochem. 20, 676-677.

24. Kanemitsu, F., Kawanishi, I. \& Mizushima, J. (1981) Clin. Chim. Acta 112, 275-283.

25. Strom, S. \& Bendz, R. (1983) Clin. Chim. Actạ 132, 73-81.

Dipl. Biochem. E. SiragEldin

Abt. für Klinische Chemie

Universitäts-Krankenhaus Eppendorf

Martinistraße 52

D-2000 Hamburg 20 